\title{
DISCURSO DE SAUDAÇÃO AO \\ PROFESSOR ANTONIO LUIS CHAVES CAMARGO, POR OCASIÃO DA SOLENIDADE DE SUA POSSE NO CARGO DE PROFESSOR TITULAR DE DIREITO PENAL
}

\author{
Guido Fernando Silva Soares \\ Professor Titular de Direito Internacional Público e \\ Vice-Diretor, no exercício da Diretoria.
}

Na auspiciosa data de hoje, em que a Egrégia Congregação da Faculdade de Direito da Universidade de São Paulo se reúne nesta especial solenidade, a fim de dar posse no honroso cargo de Professor Titular de Direito Penal, ao eminente Professor Doutor Antonio Luis Chaves Camargo, mister se faz recordar o significado histórico desta sessão particular. $\mathrm{Na}$ verdade, os grandes momentos na vida do homem em sociedade, sempre foram distinguidos de outros, através de marcas exteriores, que os fazem diferentes dos demais acontecimentos, e, para tanto, são eles cercados de ritos especiais, com a finalidade de deixar clara a importância que se atribui àquele particular instante. Não é por outra razão que o mais alto Colegiado da mais antiga e prestigiada Faculdade de Direito do Brasil se congrega, em toda sua pompa, para confirmar a um dos mais significativos atos acadêmicos, sua importância e sua relevância, para ela mesma, Faculdade de Direito, enquanto tradição, que se exige, e necessidade social, que se postula.

$\mathrm{O}$ fato de estarmos numa Faculdade de Direito, que, portanto, deve ser fiel a uma das mais prestigiadas fontes de normas comportamentais, os usos e costumes, reforça a lembrança dos momentos históricos em que a presente solenidade foi instituída. O evento tem origem na Idade Média, por volta do Século XIII, no contexto da criação das universidades, entidades essas que perduram até nossos dias, as quais têm sabido responder aos maiores desafios da história dos tempos modernos e da atualidade. A razão de tal permanência no tempo das universidades, pode ser creditada ao fato de que, até o momento, não se descobriu outra maneira de reunir, de maneira mais eficiente, de um lado, homens de ciência, pensadores de escol, espíritos despegados de valores individuais e dedicados aos superiores valores de relevância para a sociedade e, de outro, uma juventude em formação, a qual deve ser educada na linha da reafirmação dos valores históricos de todos os tempos e na descoberta de valores relevantes para o futuro.

Nascidas à sombra dos mosteiros e conventos medievais, em hipótese alguma as universidade podem relembrar as anteriores formas de educar-se a juventude: 
a academia platônica ou o liceu aristotélico. Por serem criaturas originadas no universo medieval, as universidades trazem as marcas de tal período histórico, em particular, naqueles momentos em que as exterioridades se tornam importantes, como neste momento presente. Não estamos reunidos para conferir uma coroa de louros, a um vencedor de um concurso de oratória, ou para alçar aos degraus superiores de uın pódio, um vencedor de uma competição, à maneira da Grécia clássica, mas bem, à maneira da Idade Média, para conferir uma cerimônia de investidura de novos poderes, a quem já se provou digno de envergar uma armadura de lutador, em prol da sociedade.

Trata-se, portanto, de uma cerimônia de duplo efeito: o reconhecimento de valores de uma pessoa, que já possuía qualidades especiais para determinadas funções c, ao mesmo tempo, o conferimento a ela, de novos poderes e novas responsabilidades. O agente de tal reconhecimento e de tal atribuição é a própria sociedade, a qual outorgou às universidades o papel da educação e da formação dos futuros cidadãos, e a função de ser o repositório das ciências, tecnologia e das artes e os guardiães dos valores éticos e jurídicos desta mesma sociedade.

Menos como uma particular homenagem a um grande intelectual, que seria devida ao ilustre Professor Doutor Chaves Camargo, devemos considerar a presente sessão da Egrégia Congregação da Faculdade de Direito da Universidade de São Paulo, como uma cerimônia solene com aquele duplo efeito. Em primeiro lugar, o reconhecimento dos valores éticos, profissionais e como educador, que o ilustre Professor Doutor Chaves Camargo já possuía, e que, por isso mesmo, se torna digno de integrar o Colegiado máximo, neste momento reunido, e, em segundo lugar, a investidura deste ilustre intelectual paulistano, em novos poderes, na panóplia dos poderes que se conferem aos diversos graus universitários.

Se há um traço característico da personalidade e que tem marcado toda atuação ao longo de sua vida do Professor Chaves Camargo, é sua dedicação ao Direito, na sua expressão mais alta e digna, o de ser a expressão da Justiça.

Nascido em São Paulo, Capital, a 25 de julho de 1942, filho do Senhor Francisco de Salles Camargo e de Dona Elisa Silva Chaves Camargo, ainda menor de idade, já servia ao Direito, sob a égide do Poder Judiciário paulista, ao qual iria estar integrado, tão logo terminasse sua formação acadêmica. De 13 de março de 1958, com apenas dezesseis anos de idade, já trabalhava na Secretaria do Tribunal de Justiça do Estado de São Paulo, em funções que exerceria até a 17 de outubro de 1960, ao completar dezoito anos de idade.

De 18 de outubro de 1960 a 15 de março de 1962, como acadêmico do 
Largo de São Francisco, exerceu as funções de escriturário extranumerário mensalisıa na Secretaria do Tribunal de Justiça do Estado de São Paulo, tendo, cm 1962, prestado concurso público para admissão no quadro do funcionalismo daquele Tribunal.

A partir de 17 de março de 1962, loi nomeado cscriturário técnico cm Contabilidade do Tribunal de Justiça do Estado de São Paulo, até a data de 12 de outubro de 1969, quando pediu exoneração, em virtude de haver sido nomeàdo juiz substituto, após concurso público.

Portanto, deve ser notado que durante scu Curso de Bacharelado nesta Faculdade de Direilo, o qual loi completado cm 1968, o Prol. Chaves Camargo já sc encontrava compromissado com o Direito e servia diretamente ao Poder Judiciário paulista. Deve, igualmente ser nolado, que no período de sua vida prolissional, dos inícios de 1969 , até 1980, em que o Professor Chaves Camargo esteve longe da Capital paulista, portanto, longe da sombra desta Faculdade de Dircito, por molivos do excré́cio de seu mister de magistrado, no interior do Eslado, não pôde buscar o aprimoramẹto de suas outras qualidades, como futuro prolessor de Direito. Com eleito, nomeado por concurso público na carreira da Magistratura paulista, em 31 de dezembro de 1908, como jovem magistrado, serviria em Santo André, como juiz subst.tuto para a 2 ¿ Circunscrição Judiciária, com sede em Santo André, tendo iniciado o exercício em 13 de janeiro de 1969.

Nomeado por Decreto de 01 de abril de 1970 juiz de Direito de $1^{\text {a }}$ Entrância, foi designado para a Comarca de Caconde, onde ficou até 1972, sendo, nessa data, promovido a juiz de Direito de 2: Entrância, em 20 de novembro de 1972, quando, então, seria transferido para a Comarca de Mogi Guaçu. Em 1973, a partir de 08 de agosto, foi promovido a juiz de $3^{a}$ Entrância, e removido como juiz de Dircito substituto para a Capital do Estado de São. Paulo.

Exerceu as funções de juiz de Direito auxiliar do Júri, na 2a Vara do Júri da Capital, a partir de 06 de junho de 1975, até a data de 30 de sutubro de 1979, quando seria removido para o cargo de juiz de Direito auxiliar da Capital.

Nomeado juiz de Direito da 26" Vara Cível da Comarca da Capital, São Paulo, portanto, com sua família em São Paulo, pôde o Professor Chaves Camargo dar azo à realização das potencialidades da outra vertente de sua personalidade e de seus dotes naturais, quais sejam, o gosto pela ciência, pela pesquisa e pelas atividades docentes. Admitido como professor auxiliar de Ensino no Departamento de Direito Penal da Faculdade de Direito da Universidade de São Paulo, a 23 de abril de 1981, ao finalizar a primeira etapa de seu Curso de Pós-Graduação na mesma Faculdade de Direito, no dia 10 de outubro de 1981, defende seu Mestrado em Direito Penal, com a 
dissertação intitulada Tipo Penal e Linguagem, trabalho esse que, pela sua importância para a Ciência Jurídica, seria publicado em 1982, pela Editora Forense do Rio de Janeiro, com idêntica denominação.

A partir de 19 de março de 1981, foi nomeado juiz de Direito da Vara de Menores da Capital. Entrância Especial, tendo sido promovido ao Tribunal de Alçada Criminal, aos 08 de novembro de 1984, Tribunal esse do qual exerceu a Presidência da 6. ${ }^{a}$ Câmara, pelo período de 08 de janeiro de 1986 a 30 de dezembro de 1986. Este período, sem dúvida o mais elevado na vida de um magistrado, foi para o Professor Doutor Chaves Camargo, igualmente, o mais frutuoso de sua carreira como professor universitário. Aos 06 de dezembro de 1984, defenderia sua Tese de Doutorado em Direito Penal, nesta mesma Faculdade de Direito, com o trabalho Discurso Jurídico e Direito Penal, no qual se revelam sua preocupação e seu desvelo para com a doutrina jurídica alemã mais moderna, em particular, o pensamento de Jürgen Habermas.

No que se refere à vida universitária, aos 08 de fevereiro de 1985, é nomeado professor assistente do Departamento de Direito Penal da Faculdade de Direito da USP e promovido a professor assistente-doutor, aos 05 de janeiro de 1986. A partir de então, passa a ser o responsável por inúmeras disciplinas do Departamento de Direito Penal, tanto ao nível da Graduação, quanto ao nível de Pós-Graduação, ademais das atividades de acompanhamento individual de pesquisas, orientação de trabalhos de iniciação científica, na graduação e mestrados e doutorados, em nível de Pós-Graduação, tanto na Faculdade de Direito da USP, quanto em outros estabelecimentos universitários de São Paulo.

Aos 03 de fevereiro de 1987, defendeu nessa Faculdade de Direito sua livre-docência em Direito Penal, num concurso de provas escrita, de erudição e de títulos, durante o qual sustentou em sessão pública, a tese sobre o tema: Dolo: Motivo, Vontade e Intenção. De posse do título de livre-docente em Direito Penal, foi nomeado professor livre-docente, a 17 de dezembro de 1986 e, a partir de 17 de dezembro de 1986, professor associado do Departamento de Direito Penal, desta Faculdade de Direito.

Com o deferimento de seu pedido de aposentadoria, a 12 de novembro de 1988, já no cargo de juiz do Tribunal de Alçada Criminal do Estado de São Paulo, o ilustre Professor Doutor Chaves Camargo pôde concentrar suas atividades na Advocacia, em São Paulo, tendo-se inscrito na OAB, seccional de São Paulo, Capital, e, dedicar-se sobretudo, às atividades acadêmicas. Sendo assim, com Bolsa de Estudos de PósDoutorado, outorgada pelo Governo alemão, realizou pesquisas de Pós-Doutorado no Max Planck Institut für Auslandisches und Internationales Strafrecht, em Freiburg, na Alemanha, durante os meses de dezembro de 1989 a abril de 1990, sobre o tema 
"Culpabilidade e Reprovação Penal" De tais pesquisas, resultou o importante livro Culpabilidade e Reprovação Penal, da Editora Saraiva, São Paulo, 1994, edição essa que se provou ser das mais relevantes para os estudiosos do Direito Penal no Brasil, tanto assim, que logo se esgotou e, na presente data, ainda se encontra esgotada.

Sua atividade de pesquisador continuaria, em convivência harmoniosa, com seus misteres universitários, como professor associado, tendo conseguido do Governo alemão, nova Bolsa de Estudos de Pós-Doutorado, na Alemanha. De janeiro de 1994 a abril de 1995, realizaria outras pesquisas de Pós-Doutorado no Max Planck Institut für Auslandisches und Internationales Strafrecht, em Freiburg, sobre o tema "Bioética $e$ Direito Penal". Novamente, os resultados de tais pesquisas, num campo novo e polêmico, viriam a lume, com o importante artigo, Bioética e Direito Penal, publicado na Revista Impulso, editada pela Universidade Metodista de Piracicaba, São Paulo, 1994.

Enfim, para coroar sua vida acadêmica, de 03 a 05 de março do ano corrente de 2003, o Professor Chaves Camargo submeteu-se ao Concurso de Provas e Títulos para o cargo de professor titular de Direito Penal da Faculdade de Direito da USP, com a Tese Sistema de Penas: Dogmática Jurídico-Penal e Política Criminal. Para gáudio de seus Pares da Faculdade de Direito da USP, obteve merecida e almejada aprovação, razão pela qual estamos hoje reunidos para sua investidura formal nas novas dignidades, direitos e deveres que este novo cargo lhe confere. Esta tese, que lhe rendeu o título de Professor Titular, foi publicada com a denominação Sistema de Penas: Dogmática Jurídico-Penal e Política Criminal, pela Editora Cultural Paulista em julho do corrente ano.

Nos últimos cinco anos, o Professor Chaves Camargo tem ministrado aulas nos $90^{\circ} \mathrm{e} 100^{\circ}$ semestres do Bacharelado referentes à disciplina Direito Penal Especial IV e V. Trata-se de aulas teóricas, com exposição dos temas relacionados com crimes da Parte Especial do Código Penal, bem como referência obrigatória à Parte Geral, para a compreensão do âmbito de abrangência da norma e âmbito de abrangência do tipo. Além das aulas teóricas, são realizados seminários, sobre temas do programa, e debates sobre pontos controvertidos da matéria.

De 1993 a 1999, o Professor Chaves Camargo lecionou no Curso de Pós-Graduação em Mestrado, na Universidade Metodista de Piracicaba, reconhecido pela CAPES, na área de Direito Penal; além de haver ministrado aulas, orientou inúmeros alunos e participou de várias bancas examinadoras de dissertações de Mestrado. Na Pontifícia Universidade Católica de São Paulo, desde a outorga de seu título de doutor em Direito Penal, o Professor Chaves Camargo tem integrado bancas de concurso de 
Mestrado e Doutorado na sua especialidade, alćm de haver integrado bancas de concurso público para a admissão de Professores naquela Pontifícia Universidade.

Segundo os arquivos desta Faculdade de Direito, no ano de 2000, além das aulas mencionadas, foram ministradas aulas para os $5 .^{\circ}$ e $6 .^{\circ}$ semestres do Bacharelado nas disciplinas Direito Penal I, e II, relacionadas com a Parte Especial do Código Penal, que versam sobre crimes em espécie, bem como a disciplina de Direito Penal III, Parte Especial. Nos 9. e 10. ${ }^{\circ}$ semestres, o Professor Chaves Camargo foi o responsável pelas disciplinas Direito Penal IV e V, Parte Especial, de acordo com o programa oficial desta Faculdade de Direito.

Destaquem-se as atividades de atendimento aos alunos da Graduação, durante o ano letivo, no Departamento, para orientação sobre bibliografia, pesquisas e dúvidas. Destaque-se, igualmente, que nos últimos anos, a partir de 2000 , tais orientações se têm ampliado, em virtude da apresentação por parte dos acadêmicos do curso de Bacharelado, da Monografia Final do Curso que, embora facultativa até o ano de 2007, muitos alunos se interessaram em apresentá-la, como forma de enriquecer os respectivos curricula vitae et studiorum.

Nos Cursos de Pós-Graduação, desde a obtenção do título de Doutor, em 1986, e o seu devido credenciamento pela USP, o Professor Chaves Camargo tem sido o responsável por diversas disciplinas no Departamento de Direito Penal, assim como as relevantes atividades de Professor Orientador em dissertações de Mestrado e teses de Doutoramento. Deve-se ressaltar que dois de seus alunos e orientandos na Faculdade de Direito da USP, seriam, em data posterior, admitidos como Professores da mesma Faculdade de Direito: os eminentes Professores Dr. Sérgio Salomão Shecaira e Dr. Renato Mello Jorge Silveira, ambos lotados no Departamento de Direito Penal desta Faculdade de Direito.

$\ddot{E}$ impressionante a atividade produtiva do Professor Chaves Camargo, conforme expressa pelo número de livros, artigos científicos e publicações em revistas altamente especializadas. Como livros, permito-me destacar os seguintes: Júri Organização e Jurisprudência, Corregedoria Geral de Justiça do Estado de São Paulo, São Paulo, 1981, (obra esgotada), O Menor e seus Direitos: audiência interprofissional, Lex Editora, São Paulo, 1982, Tipo Penal e Linguagem, Editora Forense, Rio de Janeiro, 1982 (esgotada), Reforma Penal (organização), Editora Saraiva, São Paulo, 1985, Júri, Editora Revista dos Tribunais, São Paulo, 1987, juntamente com co-autores: desembargador Adriano Marrey, desembargador Alberto Silva Franco e juiz Ruy Stoco. (obra esgotada), a mencionada Culpabilidade e Reprovação Penal, Editora Saraiva, 
São Paulo, 1994 (igualmente esgotada) e Impıtação Objetiva e Direito Penal brasileiro, editado pela Cultural Editora, em São Paulo, 2001.

Como artigos científicos, permito-me, igualmente, apenas destacar os campos em que o Prof. Chaves Camargo tem brilhado: Direito Penal e suas relações como o Direito Constitucional e os Direitos Humanos, a Proteção do Direito do Menor, temas de Direito Penal e de Direito Processual Penal e a Proteção dos Direitos Humanos. Neste último campo, ressalto o relevante artigo para a Ciência do Direito e para a consciência jurídica e ética nacional, do trabalho: Direitos Humanos e Direito Penal: Limites da Intervenção Estatal no Estado Democrático de Direito, in: Estudos Criminais em Homenagem a Evandro Lins e Silva (Criminalista do Século), São Paulo, Editora Método, 2001.

Deve-se colocar em destaque, a relevante participação do Prof. Dr. Chaves Camargo, em Comissões da Faculdade de Direito da USP e em colegiados dos mais significativos na vida jurídica do Brasil. Assim sendo, o Prof. Chaves Camargo integra, como Membro, a comissão de juristas da Associação de Magistrados Brasileiros, desde 1997. É membro nomeado da Academia Brasileira de Direito Criminal - ABDCrim. Recebeu da Ordem dos Advogados do Brasil, Seção de São Paulo, a Láurea de Reconhecimento por trabalho realizado. Fez parte da Comissão Editorial da Revista Impulso, da Universidade Metodista de Piracicaba, de 22 de agosto de 1999 até o ano de 2000. Na Faculdade de Direito da USP, além de membro da Congregação da Faculdade de Direito da USP, foi membro de sua Comissão de Graduação e, na atualidade, é o Presidente de sua Comissão de Pós-Graduação. Destaque-se haver o Prof. Dr. Chaves Camargo sido eleito por seus Pares, Chefe do Departamento de Direito Penal, Medicina Forense e Criminologia desta Faculdade de Direito, no período de junho de 1999 a junho de 2002 e reeleito por ainda mais dois anos.

Difícil, em poucas palavras, descrever o itinerário científico que tem percorrido o eminente Prof. Dr. Chaves Camargo. Uma característica de sua intensa atividade docente, nas suas publicações e nos seus cursos, ministrados nesta Faculdade de Direito, tanto no Bacharelado, quanto no Mestrado e Doutorado em Direito Penal, tem sido a preocupação em analisar e divulgar a evolução da dogmática jurídico-penal da atualidade, com textos que aquele Professor tem produzido, em especial após seus estágios, em nível de pós-doutorado, no Max Planck Institut für auslandisches und internationales Strafrecht, de Freiburg, Alemanha. Os esforços de atualização do Professor Chaves Camargo têm sido complementados com insistentes e constantes consultas a novidades jurídicas, como se comprova pelo depoimento de seus alunos 
que demonstram ser ele um assíduo navegante da Internet.

No pensamento do Professor Chaves Camargo e, por conseguinte, na sua contribuição à Ciência Penal, conforme praticada no Brasil, deve se dar destaque à preocupação em trazer a moderna teoria estrangeira, à discussão intelectual que se processa na Universidade brasileira. Os temas novos das implicações entre a linguagem significativa (Habermas) e o mundo normativo, encontram-se presentes na obra desse penalista brasileiro. É notável o esforço do Professor Chaves Camargo em mostrar as finalidades da pena, num Estado democrático de Direito, em contraste com as metodologias tradicionais, que consideravam o Direito Penal um sistema fechado, que se auto-explicava, dentro de um hermetismo de tipos rígidos e fundamentados numa linguagem abstrata. Propõe aquele Mestre que se considere a metodologia do Direito Penal como um sistema aberto, que sofre a influência de outros ramos da cultura e do Direito, como a Sociologia, a Lingüística, a História e a Psicologia.

$\mathrm{Na}$ esteira de pensadores modernos como Hanz Welzel, aquele ilustre Professor, que ora toma posse perante esta Congregação reunida, aponta para os fins do Direito Penal, num Estado Democrático: a proteção de bens jurídicos tutelados pelo sistema jurídico ou, ainda, a reafirmação da vigência de todo ordenamento jurídico, como uma unidade significativa global, dentro da sociedade e, enfim, a "revalidação dos conceitos valorativos num determinado momento, para um grupo social" (p. 203 de sua Tese para Professor Titular). Destaca aquele Mestre, que o bem jurídico tutelado, não mais é um conceito apriorístico ou ontológico puro, advindo de definições abstratas, mas antes, é o fruto de um agir comunicativo, tendo como referencial, o conceito valorativo sincrônico, no âmbito do grupo social. A um posicionamento clássico de considerar a atividade de todos quantos se debruçam sobre o Direito Penal e nele vêem uma atividade dogmática e de pura dedução de valores abstratos, o Prof Chaves Camargo propugna pela sua substituição por um modelo finalista, de considerar-se o Direito Penal como uma estrutura de proteção de todo o sistema jurídico, entendido como um conjunto harmonioso.

Destaque-se o cuidado do Prof. Dr. Chaves Camargo, em seu pensamento e em sua obra, de mostrar, no Direito Penal da atualidade, o abandono do posicionamento doutrinário, hermenêutico e legislativo, com fortes componentes moralizantes, do posicionamento de que a pena tem um fim meramente retributório ou de castigo. $\mathrm{Na}$ modernidade, a função da repressão penal passa a ser aquela de se constituir num sistema de prevenção geral positiva e de prevenção especial positiva, em relação a qualquer violação dos bens jurídicos relevantes para o grupo social, violação essa que 
acarreta a aplicação da pena, considerada como uma reprovação condizente com a ação ou omissão praticadas.

No base de seu pensamento, o Prof. Chaves Camargo propugna pela regra de que os princípios das Leis Magnas, ou seja, das Constituições dos Estados democráticos, sejam aqueles conducentes à, cito: adoção de um sistema aberto, integrados por categorias valorativas, permite a integração de novos conceitos, decorrentes da definição dos conflitos sociais, e, em conseqüência, determina a evolução social e o desenvolvimento da ciência jurídico-penal (citação transcrita de uma das Conclusões de sua Tese para Professor Titular).

Dentro de tal pressuposto, numa de suas conclusões na referida tese para Professor Titular, o Professor Doutor Chaves Camargo afirma, verbis, que o sistema de penas, que se caracteriza pela ordenação e unidade, dentro do sistema penal, observa, no Estado Democrático de Direito, os princípios constitucionais da legalidade, proporcionalidade, necessidade e culpabilidade.

Portanto, a partir da concepção científica do Professor Doutor Chaves Camargo, o Direito Penal nada mais seria do que um sistema de reforço a todo sistema jurídico de uma sociedade, na atualidade, profundamente ancorado nos princípios democráticos que devem ordenar esta mesma sociedade.

É um possuidor de tal sorte de pensamento democrático e de um tal posicionamento jurídico e ético, que a Faculdade de Direito da Universidade de São Paulo, neste momento, tem a honra de receber entre seus Pares, na categoria máxima de Professor Titular.

É, assim, com alegria, que os professores, alunos e funcionários da Faculdade de Direito da USP, conferimos ao ilustre Professor Doutor Antonio Luis Chaves Camargo, nesta solene tarde, as insígnias de Professor Titular de Direito Penal, certos de que Sua Excelência continuará a honrar, como sempre fez, sua vocação de bem servir ao Direito e à Justiça.

Tenho dito!!

São Paulo, dezembro de 2003. 